\title{
A Language with a Purpose - the Original Lingua Franca
}

The original Lingua Franca was a language without a nation, without native speakers, and without literature. Despite these facts, which we may easily see as severe shortcomings in the linguistics department, it was, however, a language that served its purpose. From the Dark Ages and until the onset of modernity it served as the traders' Esperanto. As such it was spoken from the Levant across the Mediterranean and to the Maghreb. Actually a quite convincing track record for a linguistically challenged language, I might add.

It seems that the original Lingua Franca emerged from the Levant, i.e. roughly the geographic region and culture zone of the eastern Mediterranean between Anatolia and Egypt, sometime during the $13^{\text {th }}$ century. Due to the fact that Lingua Franca never really became a literary medium, most of what we know of Lingua Franca today is anecdotal, but in 1353 we have the first written account of its existence. Although we lack the proper written documentation, it is believed that the crusades helped spread Lingua Franca across the Mediterranean.

Lingua Franca literally meant "speaking like the Franks". The Franks in question were not, as we might expect today, the French; rather, the term was originally used more broadly to designate all people(s) from the north of modern-day Italy. The Franks soon became a word used to describe all people(s) from Western Europe altogether; and, as a consequence of the crusades, "franchi" or "Franks" even ended up being a term used for Catholics. Lingua Franca was first and foremost a language of commerce, a language that grew out of the need of traders and merchants for haggling, negotiation and bargaining with the many communities in and around the Mediterranean.

The fact that Lingua Franca was not necessarily a written language did not mean that it was entirely without some kind of grammar or lexicon. In terms of lexicon, Lingua Franca was a simplified and reduced version of "Frankish", i.e. a mixture of - mostly - Italian with some Spanish and vulgar Latin words thrown in for good measure. Syntactically, scholars seem to agree that Lingua Franca could be described as an adaptation of a basic Italian lexicon to a simplified Arabic syntax. Speaking of grammar, it seems that the only verb form used was the infinitive, i.e. an infinitive form corresponding roughly to Romance infinitive. Even if the morphology was reduced, pluralization did occur. Moreover Lingua Franca did not feature concord between noun and adjective and only the masculine form of the adjective seems to have been used. But even if it remained a reduced language for the duration of its existence, it was not a static language; it did change over the centuries. In fact, in the hey day of Lingua Franca, two main strands had evolved: One mainly Italianinspired Lingua Franca, which was to be found mostly in the Middle East, and one IberoRomance version which was mostly spoken in the Maghreb. And here, in its "golden days" around the $17^{\text {th }}$ century, it even featured a past and future tense. 
From the year 1830 we have the first lexicographical work on Lingua Franca. It was a word list that comprised over 2000 words and which was published in Marseilles, France. The word list was meant to assist French-speaking colonials in their daily interactions with the people of Maghreb. And even if today, Lingua Franca is all but a dead language, there are supposedly remnants of the Lingua Franca numerals to be heard on the streets of old Jerusalem, where - again supposedly - children (without knowing it) sing out Lingua Franca numerals in a sort of counting-out rhyme.

Be that as it may, for all intent and purposes the original Lingua Franca is today extinct. In many ways, however, its legacy lives on. That is: When we think of Lingua Franca today not many among us think of the Esperanto of the Mediterranean, a language that emerged out of the Levant and spread along the trade routes of the Med and the Maghreb. Today we probably think of and use 'Lingua Franca' as a term for any second language used as a common denominator, as it were, when communicating across communities, be they national or cultural. In that sense the original became the mother of all pidgins.

But where does that leave the original Lingua Franca today?

In 1855, when Thomas Bulfinch wrote his seminal work on ancient mythology, he asked the question: where do Gods go when no one believes in them anymore? The answer is, I am afraid, that they go and join the languages no longer spoken in the grandest of all conservatories: the university.

\section{Author}

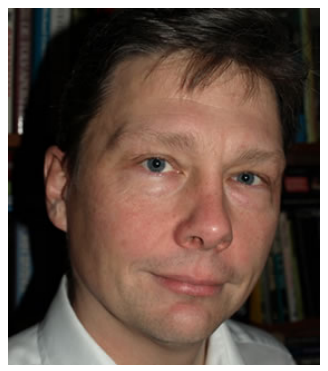

Peter Kastberg, pk@asb.dk holds a Ph.D. in applied linguistics (technical communication) and is an associate professor. He is the founder of the research area for Sociology of Knowledge, University of Aarhus, Denmark. He is currently working on his second doctorate. Among his research interests count: mediation of specialized knowledge across knowledge asymmetries, the ontogenesis of knowledge, and public understanding of science and research. 
http://en.wikipedia.org/wiki/Lingua franca

https://pantherfile.uwm.edu/corre/www/franca/go.html 